\title{
Predestinasi
}

Volume 13, No. 2, Desember 2020, Hal. 41- 52

ISSN (Print): 1978-9351

\section{Ibuanyidanda and the Principle of Non-Contradiction: A Logico-Metaphysica Discourse of Asouzu's Complementary Reflection}

\author{
Elias Ifeanyi E. Uzoigwe \\ Department of Philosophy, \\ University of Calabar, Cross River State, Nigeria. \\ *e-mail: fruzoigwe@gmail.com
}

\begin{abstract}
Ibuanyidanda and The Principle of Non-Contradiction aims at instantiating the claims of Asouzu's Complementary Reflection that whatever exists serves as a missing link of reality. Reality has been construed within a bifurcating frame of mind, a project that was characterized by the elitist mindset of Plato and was further espoused in Aristotle's philosophy of essence. For Aristotle, the wise is destined to rule the unwise. This divisive mentality permeates the entire Western culture. Unfortunately, Placid Tempels made some African scholars to erroneously believe and argue that the Western understanding of being is static, while that of Africa is dynamic. This anomaly, among other things, is what Ibuanyidanda as a philosophy and a method of doing philosophy sets out to address. Ibuanyidanda ontology contends that reality can be better understood from the complementary point of view. The principle of non-contradiction championed by Aristotle and the Western scholars sees the opposite of being as non-being, but Asouzu's complementary reflection sees the opposite of being as to be alone (ka so mu di). This work holds that ibuanyidanda complementary reflection is capable of handling the problems of contradiction that are apparent in the Western mode of philosophising. Opposites do not contradict themselves, they complement each other. Ibuanyidanda philosophy and its position are contrary to the views of Aristotle's metaphysics and open to sight ontological updating - a good recipe for the advancement of 21 st-century philosophizing. Analytic, textual, contextual, and historical methods are employed in this work.
\end{abstract}

Keywords: Complementarity; Ibuanyidanda; Non-contradiction; Ontological Updating.

\section{INTRODUCTION}

Ibuanyidanda Philosophy or Complementary Reflection seeks to show how within any framework the idea of the unity of being and consciousness is firmly grounded in the principle of non-contradiction. At the foundation of all logical reasoning both formal and dialectical, lies the principle of non-contradiction. Ibuanyidanda philosophy not only admits the co-existence of opposites but goes much further to aver and insists on their non-contradiction. However, there are situations where the principle of non-contradiction is negated. It is the position of Ibuanyidanda complementary ontology that "complementarity does not entail the idea of self-negation, and compatibility of 
contradictory opposites. These are instances where the principle of non-contradiction is negated" (Asouzu 2007d, p. 303). Things must first and foremost be themselves for them to be in a complementary relationship. They should not only affirm themselves but also should not contradict themselves. Beings in a complementary relationship are known ontologically or otherwise. In his work, The Method and Principles of Complementary Reflection in and Beyond African Philosophy, Asouzu argues that "entities confirm their existence only by entering into a relation" (2007a, p. 303).

This work strongly argues that though there may seem to be disagreement between Ibuanyidanda and the principle of non-contradiction, the fact remains that ibuanyidanda philosophy or reflection "seeks harmony through the principle of complementarity and within the context of co-existing contraries". The human mind has a lot of roles to play in both ibuanyidanda and the principle of non-contradiction. Asouzu masterfully has this to say: "In authentic complementary reflection, therefore, the mind concedes to the coexistence of opposites and tries to see how they can be related to each other in noncontradictory ways" (2007d, p. 304).

\section{A BRIEF PROFILE OF THE PHILOSOPHER, ASOUZU}

Ibuanyidanda Philosophy: A New Complementary Ontology did not fall from the sky neither are the facts it wants to establish a fictio mentics-fiction of the mind. I, therefore, consider it as a mark of logical inconsistency if I fail to articulate at least a sketchy biography of the originator and founder of this "Nobel philosophy" Ibuanyidanda Complementary Reflection. Born in Aba, Abia State on 13th October 1952 to Mazi Charles Ijeoma Asouzu (Omezioha) and Ezinne Juliana Anaezi Asouzu (Ahukaakwa), Innocent Izuchukwu Asouzu comes from Arondizuogu in Ideator-North Local Government Area of Imo State, Nigeria. He is a priest of the Catholic Diocese of Aba. Rev. Fr. Asouzu is the very first professor produced in the Department of Philosophy, University of Calabar, Nigeria. He studied in Nigeria and Austria and after his first degree in Philosophy; he further bagged masters and doctoral degrees in Sociology and Philosophy. Ibuanyidanda: New Complementary Ontology is Father Asouzu's adroit ingenuity and contribution to knowledge among other contributions he has made in Philosophy and in Humanities in general. Currently, Professor Asouzu is a household name among scholars in Africa and Europe. There is currently a journal titled: "Studies in Asouzu's Ibuanyidanda Philosophy (Complementary Reflection)". This journal is published by the Department of Philosophy and Classics at the University of Cape Coast, Ghana. Rev. Fr. Prof. Innocent Izuchukwu Asouzu is a contented, simple, and unassuming scholar of African descent with full mastery of the discipline of Philosophy, an endeavour that has occupied his time and resources for more than three decades. Asouzu has catalogue of books and academic papers published in English and German languages. 


\section{IBUANYIDANDA: A NEW COMPLEMENTARY ONTOLOGY}

Ibuanyidanda as a philosophy was founded by Rev. Fr. Prof. Innocent Izuchukwu Asouzu of the Department of Philosophy, University of Calabar, Nigeria. The concept or term ibuanyidanda has an English equivalent "complementary". As Asouzu explains:

The concept Ibuanyidanda (complementarity) provides the new ontological horizon within which we can articulate fully what it entails to be. This concept ibuanyidanda is drawn from the Igbo language and has as its nearest English equivalent the idea of complementarity in the sense of njiko ka (togetherness is greatest), igwe bu ike (strength in togetherness). The term Ibuanyidanda is a composite word made up of the following three parts: $I b u=$ load or task, Anyi=not insurmountable for, Danda $=$ danda (a species of ants) (Asouzu 2007a, p. 11).

The idea of mutual dependence and harmonization of ideas and thoughts, which ibuanyidanda philosophy champions forms the fulcrum or pedestal upon which the new complementary ontology thrives. In line with the fact that danda, in mutual dependence can carry loads that appear bigger and heavier than them suggests something very deep and significant (Bisong et al., 2016; Mendie 2020; Chukwudi 2020). It then implies that human beings and even communities just like the danda species of ants can grapple with difficult situations or challenges by complementary efforts. In his work, Gospel of Ecumenical Dialogue as the Road to Christian Unity, Ogara (2010) writes: "United we stand remains a value of timeless validity." The outstanding point here is that anything that exists has to fulfill a minimum condition, which survives in its commitment to a mutually complementary relationship between it and other units with which it shares a common framework. This is what makes existence meaningful. This is why the central thesis of Ibuanyidanda philosophy holds that, "anything that exists serves a missing link of reality...." (Asouzu 2007a, p. 10).

Ibuanyidanda philosophy goes in line with the traditional Igbo thought and mindset that there is mutual dependence observable in nature (Osuala \& Nyok 2020; Onyemachi 2020). The missing link or gap that must be filled and harmonised is a sine qua non in Asouzu's understanding because the existent realities can be in a mutual complementary relationship, as not being alone (ka so mu adina). It is in this type of situation that tension and conflict can be resolved. In his work, Ikwa Ogwe, the household name philosopher of African descent has this to say:

Since anything that exists serves a missing link, things have to be considered first and foremost in themselves to determine what they are in themselves. At the same time, they have to be considered in relation to other missing links of reality in view of determining their purpose. It is within this framework that the polarization that has hitherto characterized scientific propositions in situations of conflict can be better resolved" (Asouzu 2007b, p. 54). 
From the foregoing analysis, Ibuanyidanda Philosophy strongly holds that existence without mutual interdependence, without mutual complementary relation is no existence. Unlike Aristotle's bifurcating idea of reality, Asouzu's Ibuanyidanda: New Complementary Ontology is more encompassing and integrating where every aspect of reality is considered. Asouzu's Ibanyidanda Philosophy is a reaction against Aristotle's philosophy of substance and accident which Asouzu calls "philosophy of essence". Philosophy of essence is derived from metaphysics that is not only bifurcating in nature but polarizes and absolutises aspects of reality (Akwaji \& Paschal 2018). Ibuanyidanda philosophy tries to look at reality from a general and comprehensive perspective without seeing any aspect as inferior or superior, but complementary to each other. In the 50th Inaugural Lecture of the University of Calabar, "Ibuanyidanda" and the Philosophy of Essence, the seasoned scholar argues:

Contrary to the philosophy of essence which derives from a metaphysics that polarises and absolutises aspects of reality, the major task of an Ibuanyidanda philosophy is to show how the ego can relate to reality in a mutually harmonized non-absolutistic mode (Asouzu 2011, p. 38).

It can now be seen clearly what Ibuanyidana philosophy stands for, that is, a harmonization of reality against the Western idea of fragmentation and polarisation orchestrated by the philosophy of Plato and Aristotle's bifurcating metaphysics between substance and accident, the superior and the inferior, the wise and the unwise. In Asouzu's understanding, the so-called wise has to gain something from the supposed unwise. Ibuanyidanda philosophy is simply trying to redirect and re-educate our minds towards the understanding of the fact that no aspect of reality should be left out in the scheme of things. Each has something to offer, the physical and metaphysical, cosmological and transcendental. Still instantiating our claim, the seasoned scholar avers:

We can say that Ibuanyidanda philosophy is a transcendent, complimentary, comprehensive systematic inquiry into the structure and dynamics of human consciousness to determine the reason for the subject-object tension and dichotomy because of which the ego always seeks its autonomy outside the foundation of its unity. It is an attempt at addressing this tension to provide workable solutions towards its containment in a complementary comprehensive mutually harmonized fashion (2007a. p. 38).

Having said all these, this research did not lose sight of the fact that in Ibuanyidanada philosophy, two principles are prominent namely: the principle of integration and the principle of progressive transformation; and then the imperative of Ibuanyidanda philosophy. Instantiating this claim in well articulate words of Asouzu, he writes: "I call the metaphysical variant of Ibuanyidanda principle, the principle of integration. This principle claims: "Anything that exists serves a missing link of reality." The principle of progressive transformation serves as a practical variant of this principle. It states: "Allow the limitations of being to be the cause of your joy". Whereas the truth and authenticity criterion states: "never elevate any world immanent missing link to an absolute instance" (2011. p. 44-45). 
To round off this aspect of the study, it is of importance to note that all these principles emphasise human insufficiency while bearing in mind human determination to absoluteness and comprehensiveness in his future reference (Asouzu 2007c) bringing to sight the concatenation of substance and accident, and how being and its various modes of expression form an integral complementary whole, which Ibuanyidanda philosophy tries to espouse and establish. Essentially, it has to be indicated that the basic tools of ibuanyidanda philosophy are method, principles, truth and authentic criterion... (Ushingo 2016, p. 59). Ibuanyidada: New Ontology, therefore, sets out to synthesise, harmonise, systematise and integrate various dimensions or perspectives of reality to form a holistic and more authentic view about reality thereby reducing the tension engineered by the bifurcating and superior, inferior mentality made evident in Western philosophy, especially in the works of Plato and Aristotle, where the bifurcating and divisive foundation is laid. This must have been the reason why Asouzu insists on re-education of the mind which he technically called "noetic propaedeutic".

\section{THE PRINCIPLE OF NON-CONTRADICTION}

The principle of non-contradiction ( $\mathrm{A}$ is not non-A), is one of the fundamental principles or laws of logic. Other laws of logic include: law of identity (A is A); law of excluded middle (either A or non-A), and the law or principle of rational inference can also be applied in all the branches of philosophy, depending on the context and the ideas being reflected upon (Espinosa 2017). However, our major concern in this paper is the principle or law of non-contradiction. Aristotle's claim that a statement cannot be both true and false at the same time is a principle or law of non-contradiction and stands at the foundation of all rational reasoning. Similarly, the law of non-contradiction states that no two opposite actions can be performed at the same time and in the same relationship". By implication, this principle holds that something cannot be true or false at the same time in the same way.

\section{THE CONCEPT OF NON-CONTRADICTION AS A PHILOSOPHICAL PROBLEM}

The issue of the concept of non-contradiction is central in the discourse of metaphysics. This idea is made manifest in the first philosophy or metaphysics, which certainly deals with the ontology and first principles, where the principle of law otherwise known as the first principle or principle of non-contradiction is the firmest (Inciarte 1994). In making this concept of non-contradiction more germane, Aristotle opines that without the principle of non-contradiction we could not know anything that we do know. Interpreting Aristotle's position, he holds that, we could not demarcate the subject matter of any of the special sciences, like mathematics and biology, and we could not be able to distinguish between what something is, for instance, a human being or a snake, and what it is like, for instance, black or red. 
46 Predestinasi

Volume 13, No. 2, Desember 2020 Hal. 41-52

Nevertheless, the concept of the principle of non-contradiction raises thorny issues in many areas of modern and contemporary philosophy. For instance, relevant questions about what we are committed to by our beliefs, the relationship between language, thought and the world, and the status of arguments. Arguments from conflicting appearances about skepticism, realism and anti-realism appear to be unending. Consequently, in the principle of non-contradiction, there are arguably three versions of the principle found in Aristotle, which are; an ontological, a doxastic and the semantic version. The ontological version concerns things that exist in the world, the doxastic is about what we can believe, and the semantic relates to assertion and truth. The ontological version is usually taken to be the main version of the principle of non-contradiction and it runs as follows: it is impossible for the same thing to belong and not to belong at the same time to the same thing and in the same respect. The following are some of those qualifications: the "same thing" that belongs must be the same thing and not merely its linguistic expression. Also, the thing that belongs must belong actually, and not merely potentially; to its bearer.

The doxastic version is as follows: "It is impossible to hold the same thing to be and not to be" (Karuzis 2010). Although this version is ambiguous as it is best understood as the claim that it is impossible to hold the same thing to be false and true at the same time. As a descriptive account of human psychology, this may seem implausible, people surely have inconsistent beliefs. This is especially true if we take into account the consequences of one's beliefs. The question is, can one, knowingly believe an outright contradiction? Heraclitus, for instance, seems to say contradictory things. In his philosophical postulates, everything is in flux. For him, the only thing that does not change is change itself. This sounds contradictory because change is inclusive in "everything" he earlier claimed is in flux. For the semantic version, opposite assertions cannot be true at the same time. As it stands, this version is neutral about this internal understanding; however, Aristotle holds that any assertion involves predicting one thing of another. As with the second formation, one might give a psychological interpretation, relating to what people do affirm and deny, but the idea that opposite assertions cannot be true at the same time, suggests that this third version is better interpreted as a version of the first formulation.

The fundamental issue is that among these versions, the version Aristotle intends to establish is a matter of controversy. He could be establishing the second version on the basis of the first, or the first version on the basis of the second, or just the second version. This uncertainty obviously makes the issue of non-contradiction in philosophy quite cumbersome and problematic.

\section{THE NEXUS BETWEEN IBUANYIDANDA PHILOSOPHY AND THE PRINCIPLE OF NON-CONTRADICTION}

Asouzu's Ibuanyidanda philosophy or complementary reflection seeks to show how within any framework the idea of the unity of being and consciousness is firmly 
grounded in the principle of non-contradiction. This is the moment of complementary unity of consciousness that overcomes all forms of ambivalence, and which supersedes all forms of low-level comprehensiveness (Asouzu 2004, p. 302-303). As it were, Ibuanyidanda applies the principle of non-contradiction. It has something to do with natural law. For example, you cannot be alive and dead at the same time. If a man sees a car coming directly in front of him, he runs for his dear life.

In the opening lines of " Coexistence of contraries and contradictories; the dual fundamental human rights to err and not know reality with certainty Asuozu quoting Franz Gmainer-Pranzl observed that, "One of the major difficulties which a philosophy that is complementary in orientation has to face is that of having to address those situations that are non-complementary, that which is endemically contradictory, that which is negative and that which cannot be integrated as decisive life experience" (Asouzu 2004, p. 226).

It is necessary to say at this point that the crux of Ibuanyidanda philosophy essentially can be grasped insofar as it is understood as serving a missing link of reality. It has to be observed that most contradictory problems of mutual coexistence among human beings have very serious dispositional dimensions that cannot be ignored. Ibuanyidanda philosophy, in addressing matters of non-contradiction cannot be addressed only by making recourse to proofs and demonstrative logical reasoning and arguments. Not only that all forms of logic in an understanding of ibuanyidanda ontology have their limits, since they share in human relative insufficiency, however, "...the rules guiding ibuanyidanda logical reasoning seeks to serve as a guarantor for the validity of all forms of logic of discourse by ensuring that they comply with the demands of the transcendent complementary circle" (Asouzu 2007a. p. 91). What is this transcendental complementary circle saying? Simply put, all forms of reality, spiritual, physical, natural and preternatural complement each other and serve as a missing link of reality.

Ibuanyidanda as a philosophy and method of philosophy has brought to the 21st century philosophising the quick and urgent need for mutual complementarity among whatever that exists, to attain the greatest common good. Ibuanyidanda philosophy of mutual complementarity holds that there is a mutual dependence of all missing links in their unifying interrelatedness. Hence, all cultures, races, sexes, tribes, nations, religions and political affiliates are in mutual complementary indebtedness to each other in their privileges and responsibilities. On the other hand, the concept of the principle of noncontradiction, along with its complement, the law of excluded middle and the law of identity, partitions its logical universe into exactly two parts; it creates a dichotomy wherein the two parts are mutually exclusive and jointly exhaustive. The law of noncontradiction is merely an expression of the mutually exclusive aspect of that dichotomy, and the law of excluded middle, an expression of its jointly exhaustive aspect.

One difficulty in applying the law of non-contradiction is ambiguity in some of its propositions. For instance, if time is not explicitly specified as part of the propositions A and B, then A may be B at one, and not at another. A and B may in some cases be made to sound mutually exclusive linguistically even though A may be partly B at the same 
time. However, it is impossible to predicate of the same thing, at the same time, and in the same sense, the absence and the presence of the same fixed quality.

Ibuanyidanda philosophy argues and upholds a complementary mode of existence. This is because, according to Asouzu, "In complementarism, the mind is therefore fully conscious of its relativity and from this consciousness, it upholds its existence and makes provision for co-existence with other missing links of reality" (2007b, p. 307). Apart from seeking a discontinuity with the misidentification of things in their historical condition, it is also important to note that the unity of being is a fundamental goal the principle of non - contradiction seeks to uphold and advance. In making this point more relevant it would be recalled that "In the harmonious complementary co-existence of opposites, the mind affirms the principle of non-contradiction as lived experience. That is to say, in harmonious complementary coexistence, the mind affirms missing links of reality as moments of being existing for specific purposes" (Asouzu 2007b, p. 307).

While the principle of non-contradiction holds that a thing cannot both be and not be at the same time (Asouzu 2007b, p. 306) and in the same respect, thus making existence separate and distinct from each other; ibuanyidanda philosophy, on the other hand, holds that human existence is geared towards complementing each other. It is a case of where one fails the other supplies and vice versa. Thus, for ibuanyidanda every human coexistence, serves as a missing link of reality. Consequently, this research strongly holds that the nexus between ibuanyidanda and the principle of non-contradiction lies in the fact that the law of non-contradiction is merely an expression of the mutually exclusive aspect of that dichotomy, and the law of excluded middle, an expression of its jointly exhaustive aspect. Thus mutuality forms the basis of their connection. That is to say that, while the principle of non-contradiction is merely an expression of the mutually exclusive aspect of the dichotomy with the law of excluded middle, Ibuanyidanda philosophy, on the other hand, operates basically on mutual co-existence of human relation.

\section{POINTS OF DIVERGENCE BETWEEN IBUANYIDANDA AND THE PRINCIPLE OF NON-CONTRADICTION}

The classical source of much thought about contradiction comes from Aristotle's Metaphysics, Book 1. To this day, many of Aristotle's views have been widely rejected; the conspicuous exception, despite the work of other scholars like Dancy and Lukasiewicz, are his views on contradiction. That non - contradiction is true remains an entrenched unassailable dogma of Western thought. In recent years, due in no small measure to progress in para-consistent logic, the unassailable dogma has been assailed. Neither Aristotle's arguments for non-contradiction, non-modification of those arguments have produced strong arguments for the thesis that no contradiction is true. In as much as mutuality forms part of the basis that links the principle of non-contradiction with Ibuanyidanda, there seem to be some points of divergence that exist in the issue of contention. 
As it were, this research holds that the point of significant divergence between ibuanyidanda and the principle of non-contradiction lies in the fact that, the principle of non-contradiction holds that a thing cannot be and be at the same time and in the same respect, thus making existence separate and distinct from each other. Ibuanyidanda philosophy, on the other hand, holds that human existence is geared toward complementing each other. It is a case of where one fails the other supplies. Thus, for Ibuanyidanda, every human co-existence serves a missing link of reality. This is so because there are practical human situations that by-cut the principles of noncontradiction. For instance, when we engage in a discourse on spirits in African ontology, it is generally believed that a spirit can be more than just in a place at a particular time and in the same respect (Mbukamma 2018, p. 19). This understanding fault the idea of the principle of non-contradiction of a thing cannot be here and there at the same time. More so, in the issue of a mirage, at a distance, one simply sees a mirage on the road, but on a closer inspection, the mirage vanishes. It ceases to exist. This explains the fact that a thing in some instances can be and not be. While ibuanyidanda understands all these differences and creates room for mutual complementation, the principle of noncontradiction, on the other hand, operates with these differences distinctly. This naturally, creates a point of divergence from the two issues under debate.

\section{IBUANYIDANDA AS A PANACEA TO THE INHERENT PROBLEM OF THE PRINCIPLE OF NON-CONTRADICTION}

The law of non-contradiction has been used since the invention of language to demonstrate that, universal truth exists and that God's eye view in principle is undeniable. The law works by relying on pre propositional conditions for the speech itself, that is to say, something or anything that requires adopting a position of epistemic authority. This is the complicated way of saying that without the presupposition of objective truth, speech and argument cannot even kick-off. This is why the most popular use of the law involves exposing self-stultifications. If anyone was to deny that absolute truth exists, this denial itself will come under scrutiny, thereby turning the tables on the speaker himself. The law of non-contradiction tempts one towards lazy thinking. And so, therein lies the obscene dimension of this law. It is so engaging that it tempts us to refuse to take other worldviews seriously. The law of non-contradiction is so universal that it precisely discourages a universal attitude towards learning.

Similarly, as a result of its impact on the thought pattern of many people, especially fanatics and apologists of different religions, they tend to think of only one route in arriving at a particular destination in a religious circle. The principle of non-contradiction produces the satisfaction of making other perspectives look naive, thus ensuring that absolutist and universalist truth is the only criterion in appraising world-views. It has to 
be noted that the law itself did not explicitly say it, but in applying it, such is implied (SaraChukwuaka 2017).

The idea of Ibuanyidanda as the panacea to the inherent problem of the principle of non-contradiction is most necessary at this moment. This is given the fact that Ibuanyidanda philosophy is built on mutual complementation. Asouzu's 21st-century philosophy of complementary ontology popularly known as Ibuanyidanda has brought to the contemporary thinkers, the quick and urgent need for a mutual complementary relationship among whatever that exist, for the essential purpose of realising the common good and ensuring that the same common good thrives. Ibuanyidanda philosophy of mutual complementation holds that there is a mutual dependence of all missing links in their unifying interrelatedness. Consequently, the problems of the principle of noncontradiction can only be solved with an eye view of Ibuanyidanda philosophy, which ordinarily by nature of its philosophy, encourages mutual interdependence for better unification and mutual co-existence, which these works conceives as ontological unity in diversity.

\section{CONCLUSION}

From the above findings, it becomes clear that Asouzu's Ibuanyidanda philosophy or complementary reflection is a bold step in the right direction. The elitist, bifurcating and divisive mindset that characterised Western thought and world view was set in motion by Plato and championed by Aristotle. However, it has been seen that complementary relationship is irrevocable in so far as any discourse on reality is concerned. From another perspective, the principle of non-contradiction which holds that no two opposite actions can be performed at the same time and in the same relationship can be better understood in discourse and framework of complementary reflection because anything that exists serves a missing link of reality. It is the position of the law of non-contradiction that something cannot be both true and false at the same time in the same way.

Asouzu's contrasting view to those of Plato and Aristotle's bifurcating ontology is not a problem but is construed in this research as ontological updating. If all scholars of African and the West had accepted the impasse in the understanding of reality occasioned by Aristotle's philosophy of essence, we would not have had ibuanyidanda philosophy in the 21st-century vocabulary of philosophy. What Asouzu has done is to update the notion of reality and instantiate the claim that there is no internal division in the diverse regions of being. The submission of this research is that ibuanyidanda philosophy or complementary reflection has the capacity of handling the challenges of noncontradiction, and should be adopted as a novum organon (new method) of doing metaphysics that is grounded in logico-metaphysica (logical and metaphysical) reasoning in the 21 st century. It is so because ibuanyidanda philosophy is rich in content and also in its diversity to harmonise reality because reality comprises both the cosmological and ontological dimensions of being, and both necessarily have to complement each other for clarity and precision in grappling with reality. 


\section{REFERENCES}

Akwaji, A. G., \& Paschal, A. U. (2018). A Critique of Asouzu's Notion of The Mkpuchi Anya (the Phenomenon of Concealment). GNOSI: An Interdisciplinary Journal of Human Theory and Praxis, 1(1), 59-74.

Asouzu, I. (2004). The method and principles of complementary reflection in and beyond African philosophy. Cheedal Global Prints Ltd.

Asouzu, I. (2005). The method and principles of complementary reflection in and beyond African philosophy (Vol. 4). LIT Verlag Münster.

Asouzu, I. (2007a). Ibuaru: The Heavy Burden of Philosophy: Beyond African Philosophy (Vol. 6). Lit.

Asouzu, I. (2007b). Ikwa Ogwe: Essential Readings in Complementary Reflection: a Systematic Methodological Approach. Saesprint Publishers.

Asouzu, I. (2013). Ibuanyidanda (special Edition): Excerpt from Online Dictionary of Intercultural Philosophy (ODIP). University of Calabar Press.

Asouzu, I. I. (2007c). Ibuanyidanda: New Complementary Ontology: Beyond WorldImmanentism, Ethnocentric Reduction and Impositions (Vol. 2). LIT Verlag Münster.

Asouzu, I. I. (2007d). Ibuanyidanda: New Complementary Ontology: Beyond WorldImmanentism, Ethnocentric Reduction and Impositions. Transaction Publishers.

Asouzu, I. I. (2011). Ibuanyidanda and the Philosophy of Essence (Philosophy, the science of missing links of reality). 50 Inaugural Lecture.

Bisong, P. B., Ogar, J. N., \& Asira, A. E. (2016). The abortion debate: a contribution from Ibuanyidanda perspective. Online Journal of Health Ethics, 12(2). https://doi.org/10.18785/ojhe.1202.06

Christian Unity, Enugu.

Chukwudi, O. F. (2020). The Principle of Common Good in Ibuanyidanda Philosophy and Egocentrism in Nigeria's Political Leadership. PINISI Discretion Review, 4(1), 93.

Encyclopedia Britannica Student and Home Edition. Chicago: Encyclopedia Britannica, 2009.

Espinosa, R. G. (2017). Principle of non-contradiction in the necessity defense. Revista de Derecho (Valdivia), 30(2), 367-389.

Inciarte, F. (1994). Aristotle's Defence of the Principle of Non-Contradiction. Archiv Fur Geschichte Der Philosophie, 76(2), 129-150.

Karuzis, J. (2010). The Principle of Non-Contradiction in Aristotle's Metaphysics. International Journal of Arts and Sciences, 3(16), 231-254.

Mbukamma, F. C. (2018). Basic Issues in Logic. Ibadan: Shola Prints.

Mendie, J. G. (2020). Metaphysics and the Method of Ibuanyidanda. GNOSI: An Interdisciplinary Journal of Human Theory and Praxis, 3(1), 32-39.

Ogara, P. I. (2009). United We Stand: Gospel of Ecumenical Dialogue and Road to 
$52 \mid$ Predestinasi

Volume 13, No. 2, Desember 2020 Hal. 41- 52

Onyemachi, F. C. (2020). Complementary Leadership: A Neglected Key to National

Security Issues in Nigeria. GNOSI: An Interdisciplinary Journal of Human Theory and Praxis, 3(1), 76-84.

Osuala, A. N., \& Nyok, E. I. E. (2018). New Twist to Political Corruption in 4th Republic Nigeria given Non-Human Animals Stealing millions: A Case for the Defense of Animal Rights. GNOSI: An Interdisciplinary Journal of Human Theory and Praxis, 1(2), 15-37.

Sarachukwuaka, E. (2017). Philosophy for The Beginners, Enugu: Phoenix.

Ushingo, Peter. U. (2016). Comparative Analysis of Plato's Concept of Education and Asouzu's Ibuanyidanda Philosophy M.A Thesis Submitted to the Department of Philosophy University of Calabar. 